\title{
A system dynamics approach to technology sustainability assessment: The case of biodiesel developments in South Africa
}

\author{
Josephine K. Musango $^{\mathrm{a}, \mathrm{b}, *}$, Alan C. Brent ${ }^{\mathrm{b}}$, Bamikole Amigun ${ }^{\mathrm{c}, \dagger}$, Leon Pretorius ${ }^{\mathrm{d}}$, Hans Müller ${ }^{\mathrm{e}}$ \\ a Gauteng City-Region Observatory, a partnership between the University of Johannesburg, the University of the Witwatersrand, Johannesburg and the Gauteng Provincial \\ Government, Private Bag 3, Wits, 2050, South Africa \\ ${ }^{\mathrm{b}}$ Centre for Renewable and Sustainable Energy Studies; School of Public Leadership, Stellenbosch University, Sustainability Institute, South Africa \\ ${ }^{\mathrm{c}}$ Renewable Energy Group, National Biotechnology Development Agency, a parastatal under the Federal Ministry of Science and Technology, Abuja, Nigeria \\ ${ }^{\mathrm{d}}$ Graduate School of Technology Management, University of Pretoria, Pretoria, South Africa \\ ${ }^{\mathrm{e}}$ Centre for Knowledge Dynamics and Decision-making, Department of Information Science, Stellenbosch University, Stellenbosch, South Africa
}

Keywords:

Technology assessment

Sustainability

Bioenergy

Renewable energy

South Africa

\begin{abstract}
A B S T R A C T
This paper suggests that a system dynamics approach is best suited to assess the sustainability of technologies, with a specific emphasis on policy interventions for renewable energy in the African context. A bioenergy technology sustainability assessment (BIOTSA) model is subsequently demonstrated by analysing the outcomes of a proposed biodiesel production development on selected sustainability indicators for the Eastern Cape Province of South Africa. In addition, some scenarios are tested to compare how they may improve the selected indicators. The BIOTSA model results are useful to compare dynamic consequences that may result from the proposed biodiesel production development and the respective policies and decisions that may arise from such a development. Nevertheless, recommendations are made to improve the usefulness and practicability of this type of model for technology assessment purposes.
\end{abstract}

\section{Introduction}

Technology assessment is an important component of the effective management of technology (Musango and Brent, 2011a, 2011b) and occurs in initial technology life-cycle phases (Brent and Pretorius, 2008) A summary of the development of technology assessment over the last four decades has been provided (De Piante Henriksen, 1997; Tran and Daim, 2008). The emergence of organised technology assessment, as a formal procedure, was, first and foremost, an attempt to predict the unintended negative consequences of technical innovations in the market uptake cycle of technologies (Afgan and Carvalho, 2002) to facilitate more adequate policy-making. An expectation of technology assessment was that it should reveal the future consequences of new technology that otherwise would not have been recognized (Jones, 2008).

With respect to renewable and clean energy technology development, some studies acknowledge the need to analyse

\footnotetext{
${ }^{\dagger}$ Deceased.

* Corresponding author.

E-mail addresses: Josephine.musango@gcro.ac.za,

jkaviash@yahoo.com (J.K. Musango), acb@sun.ac.za (A.C. Brent),

koleamigun@nabda.gov.ng (B. Amigun), leon.pretorius@up.ac.za (L. Pretorius),

hpm@sun.ac.za (H. Müller).
}

the developments as complex systems (Afgan and Carvalho, 2002; Jones, 2008; Synder and Antkowiak, 2010). Thus, the approach to use to assess the sustainability of such technologies will need to be in a position to account for the assumptions regarding sustainable development (Brent, 2009; Musango and Brent, 2011b). This includes the economic, environmental, social, institutional, and other changes that might influence the development of a technology towards a desired sustainable path. System dynamics, it has been argued (Kilham and Willetts, Undated; Jones, 2008; Musango and Brent, 2011b), provides the potential for such an assessment.

System dynamics is a transdisciplinary and interdisciplinary approach that is based on the theory of system structures (Sterman, 2000), and is utilized to represent complex systems by analyzing their dynamic behavior over time (Forrester, 1994). While system dynamics is recognized as one of the tools for technology assessment (De Piante Henriksen, 1997; Tran and Daim, 2008), it has had limited application in the technology management community. It has previously been used in technology transition and diffusion (Kim, 2003; Meyer and Winebrake, 2009); technology innovation (Rose-Anderssen et al., 2005; Lin et al., 2006; Galanakis, 2006); knowledge transfer and proximity effects on technology districts (Dangelico et al., 2010), among others. For the case of renewable energy technology development for sustainability, a conceptual framework of a systems approach to technology sustainability assessment (SATSA) has been 
developed (Musango and Brent, 2011a); with the intention to improve sustainability assessment practices for renewable energy technologies in emerging markets. SATSA aims to demonstrate the linkages between key elements, namely, technology development, sustainable development, and a dynamic systems approach that are suggested as vital for improved practices of sustainability assessment of technologies. These combined elements provide the understanding of sustainable technology development, technology assessment, and sustainability assessment and form the basis for SATSA (see Fig. 1).

The main contribution of this paper is to apply the SATSA framework to assess the sustainability of biodiesel development in South Africa. The paper provides system dynamics simulation results by exploring specified, but complex, relationships between social, economic and environmental sub-systems in the development of biodiesel production in South Africa. The results follow on the paper of Musango et al., (2011), which provides the details of an introduced bioenergy technology sustainability assessment (BIOTSA) model. In this paper, the model is utilised to determine the effects of a proposed biodiesel development in the Eastern Cape Province of South Africa in terms of selected sustainability indicators. A number of scenarios are used to explore the extent to which they affect the selected sustainability indicators. The findings of this study aims to inform policy- and decision-making pertaining to the appropriateness of biodiesel technology for sustainable development in South Africa.

\section{The case of biodiesel production development}

Recently, there has been a growing interest in biodiesel production development. This is because biodiesel is a cleaner and alternative liquid fuel to petroleum diesel that can be used in normal diesel engines with little or no modifications (Basha et al.,

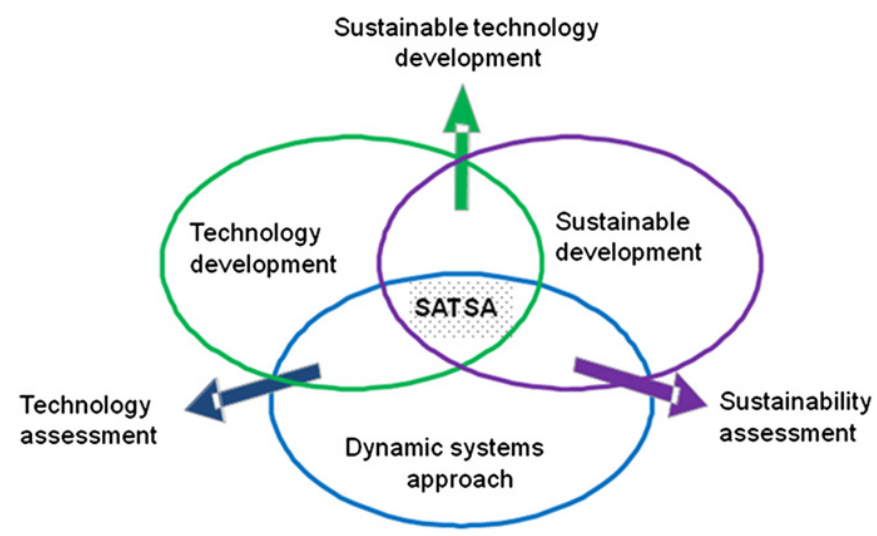

Fig. 1. Schematic representation of a systems approach to technology sustainability assessment (SATSA); Adapted from Musango et al. (2011a).
2009). In addition, biodiesel has the potential to contribute towards sustainable development (Sukkasi et al., 2010; Amigun et al., 2011b). To this end, the main drivers for developing a biodiesel industry include, among others: (i) the potential of reducing greenhouse gases; (ii) the potential for rural development through job creation and agricultural diversification; and (iii) the potential to secure domestic energy supply from locally grown crops, thus reducing imports of foreign oil or promoting exports of locally produced oil (Blagoev, 2008).

A number of countries have been active in biodiesel production and programmes, with Europe and the United States leading the industry. Other countries have drawn up strategies to support biodiesel production. South Africa has had a long, but inconsistent history in the field of biodiesel development (Pahl, 2008). Nevertheless, the biodiesel industry in South Africa is still in its infancy and is characterised with small- to medium-scale production (Amigun et al., 2008b). Major concerns for entrepreneurs in this sector are feedstock cost (virgin oils for biodiesel is expensive), uptake (no mandatory blending) and meeting the specifications that are required by petrochemical industries (Van Zyl and Prior, 2009). The South Africa Biofuels Industrial Strategy identifies canola, soybean and sunflower as the feedstock for large-scale biodiesel production (Department of Minerals and Energy, 2007).

Biodiesel development, as with any other bioenergy, is now recognized as complex systems that involve many stakeholders, particularly the vulnerable rural poor (Sukkasi et al., 2010). The production chain for biodiesel and the different actors involved is illustrated in Fig. 2. In addition, the issue of sustainable development has become a top priority of many government policies. South African governance in particular is developing national measures of sustainability (Brent and Rogers, 2010). Thus, while biodiesel development is expected to grow, it is important to ensure that it is sustainable (Sukkasi et al., 2010). Ensuring sustainable biodiesel development requires taking a holistic view of biodiesel production and assessing its effects on key sustainability indicators.

\section{Methodology: A system dynamics approach}

The bioenergy technology sustainability assessment (BIOTSA) model is based on the conceptual framework of a systems approach to technology sustainability assessment (SATSA) (Musango and Brent, 2011a). The emphasis in system dynamics, as part of the SATSA framework, is on structure and assumes that this best represents the dynamic behaviour of the "real world" (Flood and Jackson, 1991). System dynamics can capture the complex realworld behaviour of uncertainties that result from non-linear feedback structures (Forrester, 1994; Sterman, 2000). As a result, system dynamics modelling has a wide application in different disciplines, including: business marketing and management, environmental management, and health care, amongst others.

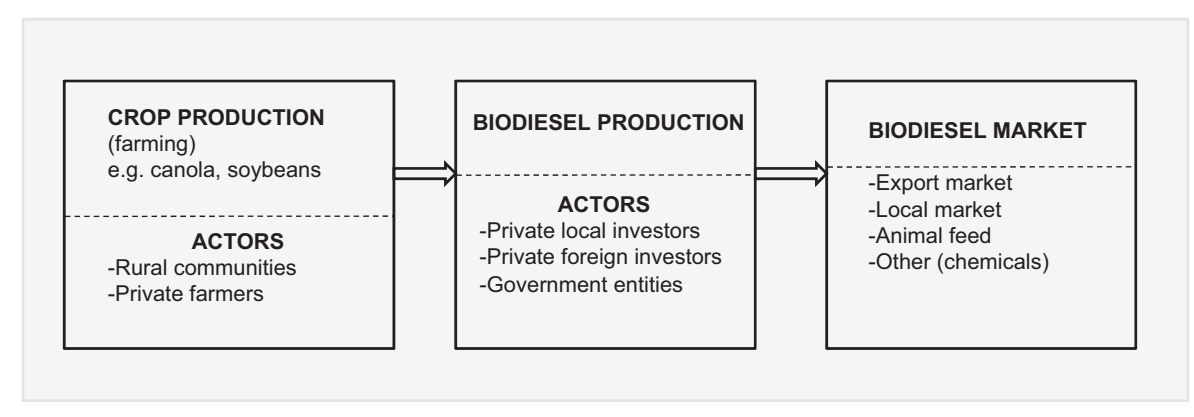

Fig. 2. Illustration of actors in the biodiesel production chain; Adapted from Musango et al. (2011). 
From a technology sustainability assessment perspective (Assefa and Frostell, 2006), system dynamics recognizes sustainability as a whole systems concept concerned with human activities in the context of naturally occurring systems. This provides the sources and sinks for the flows of materials and energy associated with them, and the ability of those systems to sustain human activities (Chan et al., 2004).

The use of system dynamics to assess the sustainable development of biodiesel production is limited. A number of studies have, however, used system dynamics to examine various aspects of biodiesel development. Bantz and Deaton (2006) explore how, and to which extent, biodiesel growth in the United States is influenced by factors such as: feedstock prices, production technologies, product/co-product prices, and government incentives or regulations. Their focus was biased towards assessing the profitability of the biodiesel industry. Hidayatno et al., (2011) focussed on the effects of government policy for stimulating biodiesel industry. Their study included four sustainability indicators namely, biodiesel production; employment; financial indicator and net emissions. The BIOTSA model that has been introduced (Musango et al., 2011) provides information on the sustainability of a biodiesel system for a range of indicators.

\section{Model description}

This study used the Vensim ${ }^{\circledR}$ software as a platform for the BIOTSA model to conceptualize, simulate and analyse the biodiesel production development in the Eastern Cape Province of South Africa. The Vensim ${ }^{\mathbb{R}}$ software provides a flexible and simple platform for building simulation models for both causal loop diagrams or stock and flow diagrams (Ventana Systems, 2003). The general modelling process in the Vensim ${ }^{\circledR}$ software starts with the outline of the model and definition of the variables. The relationship between the variables is also specified numerically using equations. This is then followed by model simulation and scenarios analyses, and the results are observed using analysis tools, such as tables and graphs, to determine the dynamic behaviour of some key model variables and their differences in different scenarios.

There are eleven sub-models in the BIOTSA model, namely: biodiesel production cost of operation, biodiesel production profitability, gross domestic product (GDP), employment from a biodiesel plant, community acceptance, population, land usage, water usage, air emissions, and energy demand. A simplified causal-effect relationship between the variables in the eleven sub-models is visualized as the causal loop diagram in Fig. 3.

A project-wide scope was used for the BIOTSA model. This was necessary to ensure that both down- and upstream effects of decisions for the biodiesel production development were accounted for. Confining this to a project-wide scope also ensured that the scenarios were tested within the realm of the responsibility of the model users. For instance, while a biodiesel technology developer may have influence on the overall biodiesel production level, venturing beyond the boundaries of a biodiesel project level could reduce the relevance and feasibility of scenarios; hence reducing the models usefulness and practicality. The full details of the contents and structures of the eleven submodels are described in Musango et al. (2011).

\subsection{BIOTSA model assessment and scenario definition}

The BIOTSA model was exposed to a number of validation tests: structural validity, behavioural validity, and expert opinion (Musango et al., 2011). The validation process was aimed at improving the confidence of the BIOTSA model, to ensure that it generated the "right behaviour for the right reasons".

Given that the BIOTSA model assesses the sustainability of biodiesel development, a time horizon from 2005 to 2100 was used. This was done in order to take into account the short-, medium- and long-term effects of the biodiesel development on the selected sustainability indicators. In addition, in order to support the comparison of the results, a number of scenarios were defined to test the responses of the sustainability indicators to changes in fertilizer use, community perception, support for biodiesel, and by-product use.

\section{Model application to technology sustainability assessment}

The case example for this assessment was the development of the biodiesel industry in the Eastern Cape Province of South Africa (see Fig. 4). Biodiesel production development is part of a new agrarian transformation plan for the Province and among the

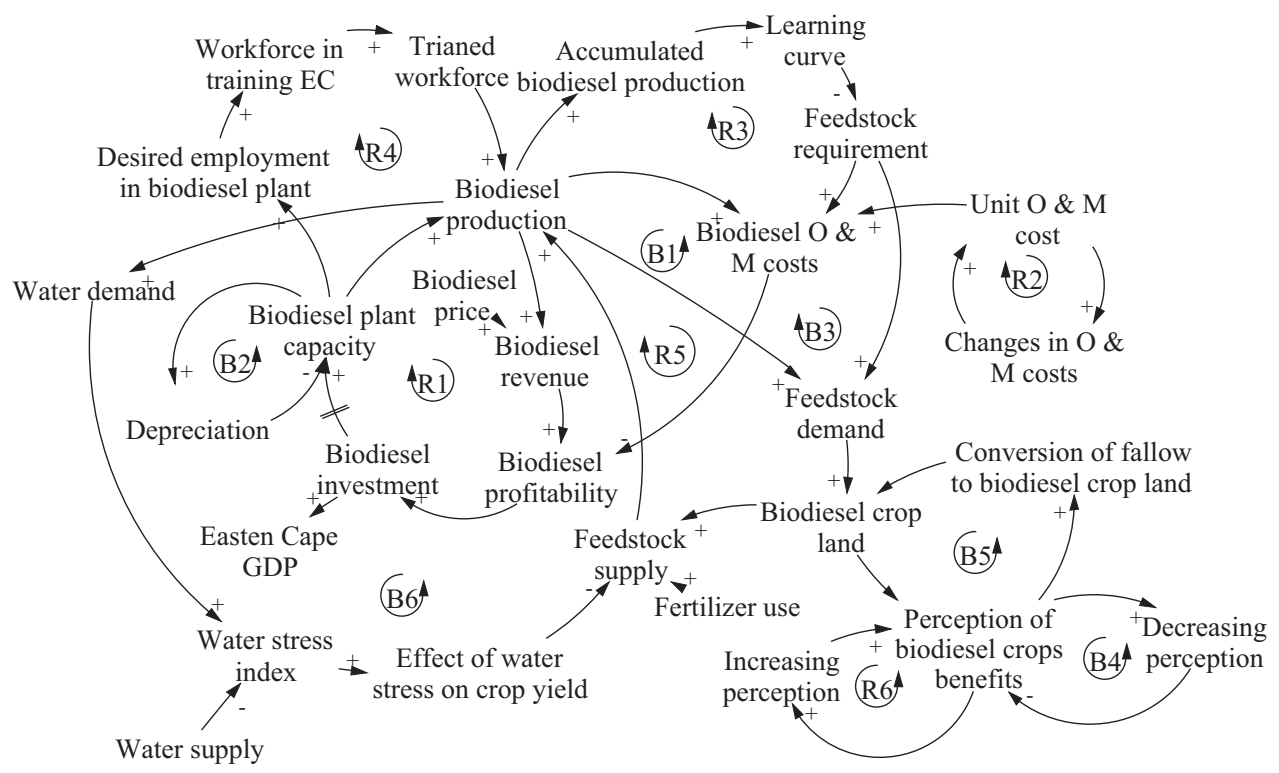

Fig. 3. Causal loop diagram for biodiesel production. 


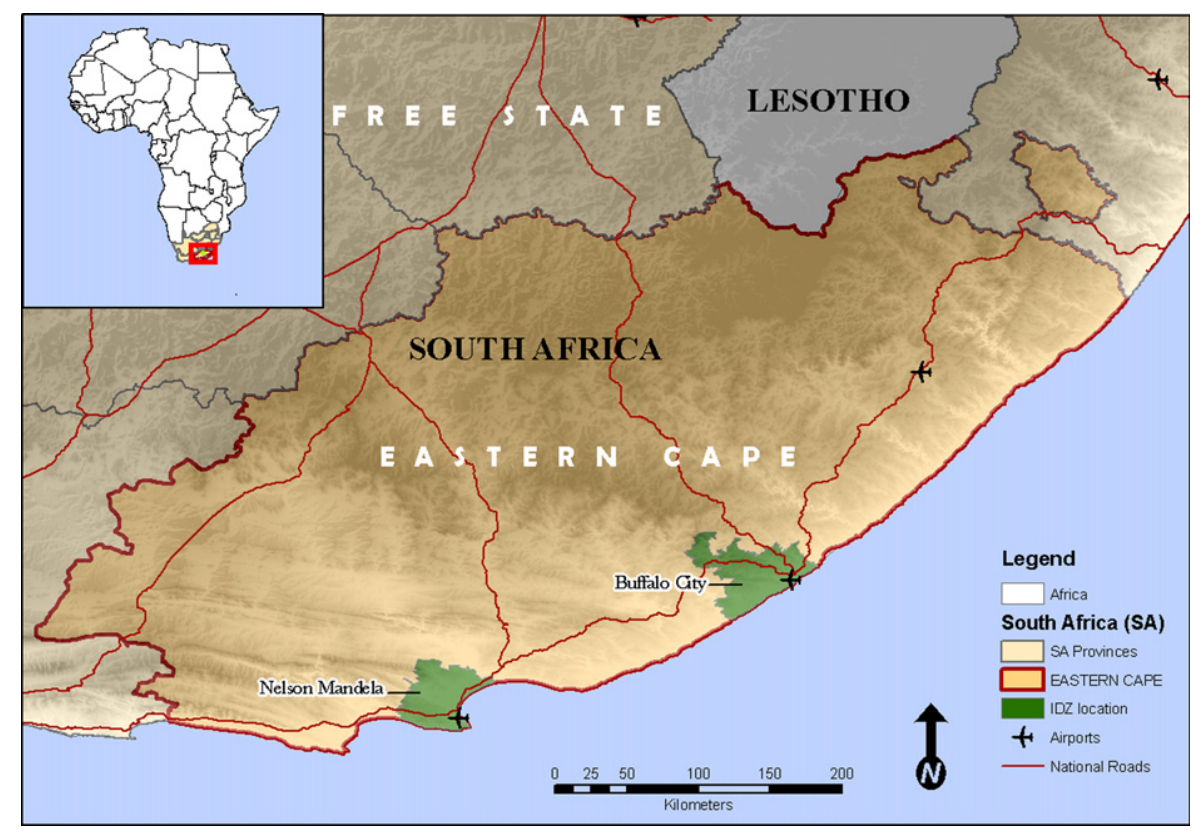

Fig. 4. Map showing the case study location.

Table 1

Sustainability indicators for bioenergy technology assessment in Eastern Cape. Source: Musango et al. (2011).

\begin{tabular}{|c|c|c|c|}
\hline Indicator & Symbol & Description & Units \\
\hline \multicolumn{4}{|l|}{ Economic } \\
\hline Biodiesel production & ECO1 & This measures the quantity of biodiesel production. & Litre/year \\
\hline Biodiesel profitability & $\mathrm{ECO} 2$ & This measures the profitability from biodiesel production. & USD/year \\
\hline Eastern Cape GDP & $\mathrm{ECO} 3$ & This measures the per capita GDP in the Eastern Cape Province. & USD/person/ year \\
\hline \multicolumn{4}{|c|}{ 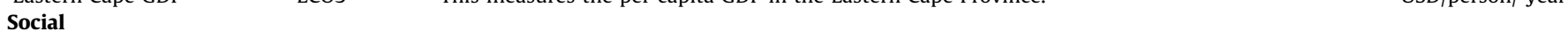 } \\
\hline Employment & SOC1 & $\begin{array}{l}\text { This measures the labour force participation due to the investment in the biodiesel } \\
\text { plant capacity. }\end{array}$ & Person \\
\hline Community perception & SOC2 & $\begin{array}{l}\text { This is represented by the effect of community perception on land conversion for } \\
\text { biodiesel production crops and measures the community acceptance to grow these crops. }\end{array}$ & Dimensionless \\
\hline \multicolumn{4}{|c|}{ 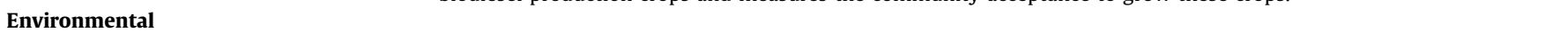 } \\
\hline Land use change & ENV1 & $\begin{array}{l}\text { This measure the changes in land use due to the introduction of biodiesel production. } \\
\text { This includes changes in fallow land, agricultural land, biodiesel crop land and livestock land. }\end{array}$ & $\mathrm{Ha}$ \\
\hline Air emission & ENV2 & This measures the total avoided air emissions due to investment in biodiesel production & $\mathrm{kg} \mathrm{CO} /$ year \\
\hline Biodiesel by-product & ENV3 & This measures the amount of accumulated glycerol resulting from biodiesel production. & Litre \\
\hline Water use & ENV4 & This measures water use as a result of biodiesel production. & Litre/Year \\
\hline Energy use & ENV5 & This measures energy use as a result of biodiesel production. & $\mathrm{KW}$ h/Year \\
\hline
\end{tabular}

priority projects under the Accelerated and Shared Growth Initiative for South Africa (ASGI-SA). ASGI-SA is a nationally supported initiative, intended to promote economic growth and reduce unemployment in the country. While currently there is no commercial biodiesel production in existence, several projects are planned for development in the Eastern Cape Province. Among these projects are the plans are to build a biodiesel plant that utilizes canola as a feedstock and has a production capacity of about 400 million metric tonnes http://www.phytoenergy.org/. Although canola is not cultivated in the region (Eastern Cape Province), the project aims to avoid the usual food insecurity criticism associated with biofuels, as canola is a winter crop that would be cultivated in rotation with maize or wheat, which are summer crops.

The planned biodiesel refinery for this project is likely to be in an Industrial Development Zone (IDZ) in the Nelson Mandela Municipality of the Eastern Cape Province (see Fig. 4). IDZ's are purpose-built industrial estates geared for duty-free production for exports, and they play a significant role in South Africa's macroeconomic policy. They provide transport, logistics and business services tailored for export-oriented industries. The biodiesel produced from this project is destined for the European market, where "cold proof" fuel, which can be used in winter in Europe, is required.

Given that the intention of the study is to assess the biodiesel production development in the Eastern Cape Province, sustainability indicators related to such a development, as identified and defined by Musango et al. (2011), were used (see Table 1). The economic indicators are associated with the performance of the biodiesel production plant and the economy of the Eastern Cape Province. Social indicators show the employment created in the biodiesel production plant and the community acceptance to cultivate biodiesel crops. Finally, the environmental indicators represent the emissions, water, energy, waste (particularly glycerol) and land use changes resulting from the introduction of biodiesel production in the Eastern Cape.

\subsection{Scenario overview}

The study defined six scenarios that were used in the BIOTSA model to evaluate the impact of biodiesel production development on the selected sustainability indicators (of Table 2). The 
Table 2

Scenarios analysed in BIOTSA model.

\begin{tabular}{|c|c|c|}
\hline $\begin{array}{l}\text { Scenario } \\
\text { number }\end{array}$ & Scenario name and abbreviation & Description \\
\hline & Baseline & $\begin{array}{l}\text { It represents a situation where the current South Africa strategy of supporting biofuel production is maintained. The } \\
\text { scenario also assumes that a proposed biodiesel investment project, by an international company that intents to } \\
\text { export biodiesel, is kept, and that the plant will be operational in } 2012 \text { as per the company's expectations. }\end{array}$ \\
\hline 1 & Fertilizer use & $\begin{array}{l}\text { This represents a situation where the local community makes use of fertilizer as opposed to the baseline scenario } \\
\text { where there is no use of fertilizer. }\end{array}$ \\
\hline $2 a$ and $2 b$ & Biodiesel support & $\begin{array}{l}\text { This considers two support situations. The first one is where the investor is subsidised for biodiesel production as } \\
\text { outlined in the South Africa Biofuels Industrial Strategy. The second situation is a hypothetical one and considers a } \\
\text { situation where the support is doubled. }\end{array}$ \\
\hline 3 & By-products use & $\begin{array}{l}\text { This considers a situation where the biodiesel glycerol by-product is part of revenue generation in the biodiesel } \\
\text { production. }\end{array}$ \\
\hline 4 & Community perception & $\begin{array}{l}\text { This scenario takes a situation whereby the community perception is relatively high A survey in, and visit to, the } \\
\text { Eastern Cape Province revealed that the communities' knowledge and understanding of the biodiesel crops benefits } \\
\text { remain relatively low. }\end{array}$ \\
\hline 5 & $\begin{array}{l}\text { Support and by-product use } \\
\text { scenario }\end{array}$ & This is a combined scenario of biodiesel support and by-product use. \\
\hline 6 & $\begin{array}{l}\text { Perception, support and by- } \\
\text { product use scenario }\end{array}$ & Another combined scenario included a high initial community perception, biodiesel support and by-product use. \\
\hline
\end{tabular}

a

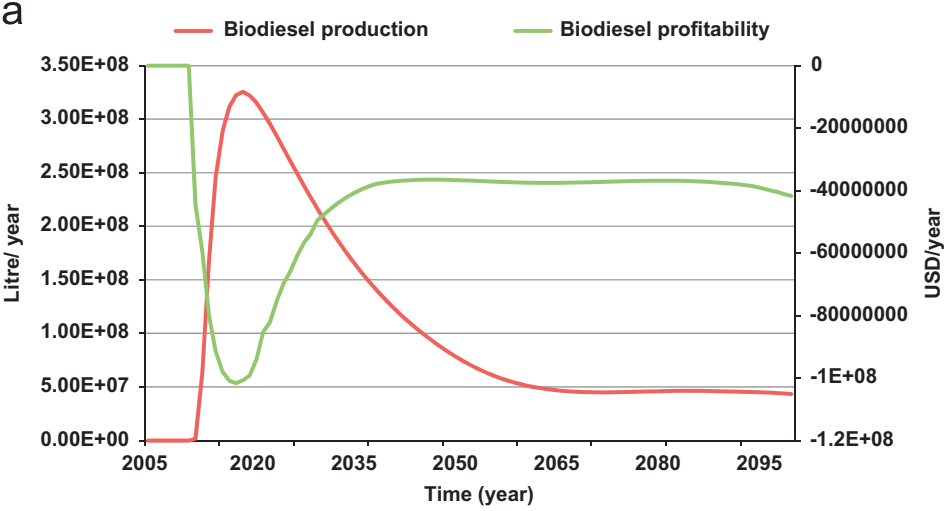

b

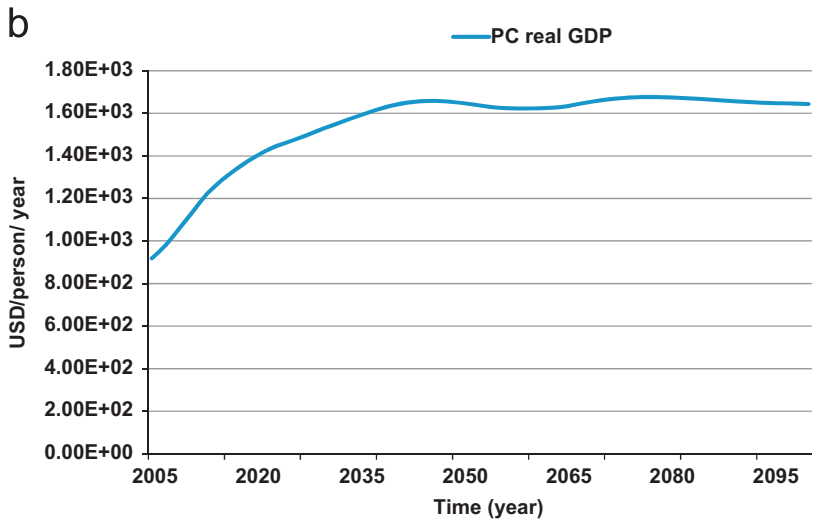

Fig. 5. Graphical output for economic indicators of the BIOTSA model.

scenarios that are defined are characterised by the different values of the following variables: (i) fertilizer use, where 0 represents a situation where fertilizer is not used in the cultivation of biodiesel crops (canola) and 1 represents the use of fertilizer; (ii) biodiesel support, represents the amount of support in form of subsidy that the biodiesel investors receive for biodiesel production; (iii) the by-product use, where 1 represent a situation where the biodiesel plant by-products, particularly glycerol, is used in a productive way, thus generating revenue to the biodiesel plant, and zero when not part of revenue generation; and (iv) community perception, where the different initial values are utilized representing the low and high level of acceptance to grow biodiesel crops (see Table 2). The simulated results for the different scenarios are presented in the sub-sections that follow.

\subsection{Scenario: Baseline}

This is the baseline situation that is used as a reference for comparing results with the defined scenarios 1 to 6 . The baseline scenario presents a situation where the biodiesel production is assumed to be operational in 2012 as per the investors' expectations. Other assumptions that were made include: (i) the operational costs for biodiesel production, in particular, feedstock, water cost, energy cost and other operational costs, grows at $0.1 \%$ over time; (ii) the community perception to participate in biodiesel crop production remains relatively low, implying that there will be less supply of local feedstock and that the investors will be required to source the feedstock from imports; (iii) the producers of biodiesel crops are not utilizing fertilizer in their farming practices since they are mainly rural communities; and (iv) the government is not providing support in form of subsidies to the farmers and the investors for their crop and biodiesel production, respectively.

Based on these assumptions, the baseline simulation runs for the economic indicators are presented in Fig. 5. With the biodiesel production projected to start from 2012, a maximum production capacity of about 326 million litres per year is reached in 2019, and thereafter starts to decrease. The factors influencing the dynamics of the biodiesel production and future expansion include: feedstock availability and price; land availability; and expected profitability. The expected profitability is not enough to encourage more desired capacity expansion. In addition, the production level declines to match with the local feedstock availability or supply.

The biodiesel plant developers propose to use an agrarian (agriculture) model, whereby they initially expect to source feedstock from imports because canola is not currently grown in the Eastern Cape Province. The imports are expected to decrease as the feedstock production in the Province increases. However, given the low initial perception as indicated in the baseline scenario, the local supply of feedstock is constrained resulting in a reduction of desired biodiesel production. The low 
initial perception used in the baseline scenario is based on the evidence that people are reluctant to implement new activities or technologies that are introduced to them, especially those that involve a shift in paradigm. Evidence concerning the low perception includes: lack of trust, incredibility and past bad experiences; as reported by Amigun et al. (2011a). It might take some time to change the mindset of the communities so that they would be willing to grow crops for biodiesel production.

Biodiesel profitability is another economic indicator for the performance of the investment in the biodiesel production value chain (see Fig. 5). The BIOTSA model indicates that high losses are incurred in 2012, which is a result of the capital cost outlay prior to the production. From 2013, however, due to the start of the biodiesel production, the capital cost is covered but still the operation is not profitable. The per capita real GDP in the Eastern Cape Province on the other hand shows a relatively modest growth of 39\% relative to 2012 (Fig. 5).

The simulation output for the social indicators is presented in Fig. 6. The employment in the biodiesel plant is projected to increase, reaching a maximum of 203 persons in 2020 (Fig. 6). Thereafter, the employment declines due to the decrease in the functional biodiesel capacity. While biodiesel production development is claimed to create employment in the farming communities, only the employment in the biodiesel plant was taken into account. This is because the level of information on employment in the whole supply chain is unavailable. In addition, the land that is planned for biodiesel crop production is in the rural areas where the communities are currently doing substance farming. It

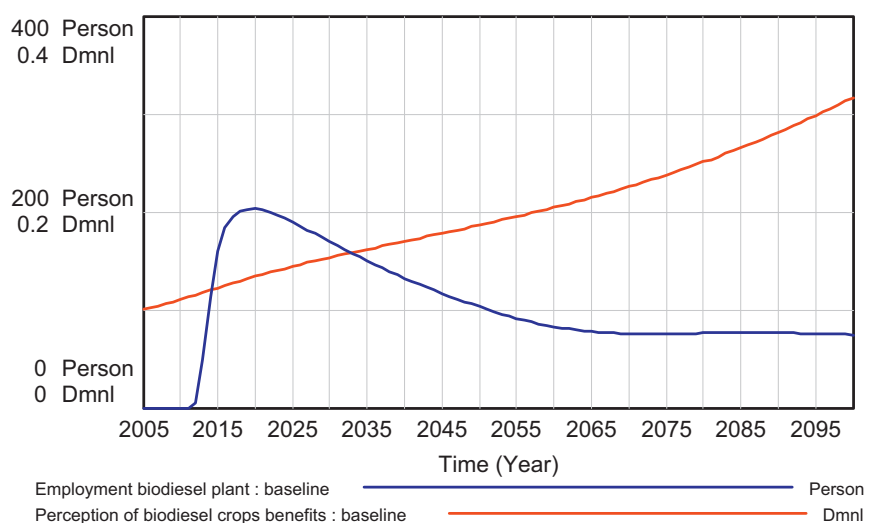

Fig. 6. Graphical output of social indicators of the BIOTSA model.

a

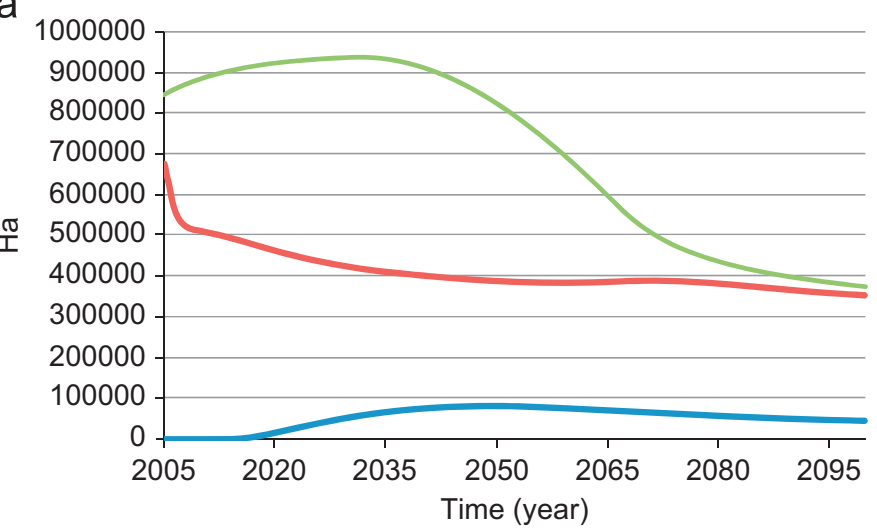

— Biodiesel crop land _ Fallow land — Forest plantations was challenging to determine the extent to which crop production for biodiesel will actually create new employment or whether it would expand or replace the current crop basket being farmed. This was therefore excluded from the model. However, it is possible and important to consider this aspect when assessing biodiesel production development.

Land is an important asset in the Eastern Cape Province and the communities consider it is as their inheritance (Amigun et al., 2011a). Thus, the community perception on biodiesel crops benefits is an important social indicator for biodiesel production development. As observed in Fig. 6, the model projects an increase in the community perception over the simulation period because only a small proportion of fallow land is converted into biodiesel crop land. If large portions of this land were converted, the community would perceive that the land is being taken away from them, which, in turn, would decrease their perception of biodiesel crops benefits.

The baseline results are also presented for the five environmental indicators (see Fig. 7). Land use change is associated with the assumption that biodiesel cropland is only acquired from fallow land, which also competes with other land uses. The size of fallow land is therefore observed to decrease over the simulation period. Biodiesel cropland on the other hand increases from zero in 2011 and reaches a maximum land size in 2050. Henceforth, the biodiesel cropland declines over the simulation period. In a similar manner, forest plantation increases at a decreasing rate and reaches a maximum land size in 2033. Thereafter, the forest plantation declines at a decreasing rate. For the case of the cropland, the model projects a $83 \%$ increase in land size relative to 2012. This increase is largely driven by the increase in population. The same case applies to settlement land, which also increases over the simulation period due to the increase in population.

The air emissions indicator is associated with the air emissions avoided due to biodiesel production. Given that the case considered here is for a biodiesel product that would be used outside South Africa, this indicator becomes important in terms of negotiations in the carbon trading market and policy arena. As observed in Fig. 8, the emissions follow the biodiesel production dynamics and a maximum air emission avoided, of 390.61 million $\mathrm{kg} \mathrm{CO}$ per year, is reached in 2019 and declines thereafter as biodiesel production declines as well.

Similarly, the glycerol by-product, water use and energy use follow the similar trends of the biodiesel production (see Fig. 9), since these indicators are mainly influenced by the extent of biodiesel production development.

b

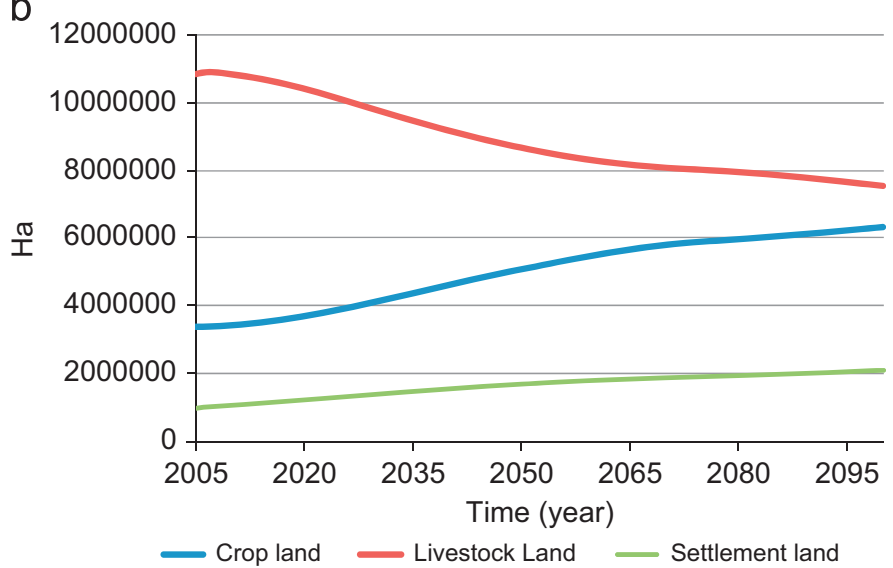

Fig. 7. Land use environmental indicator of the BIOTSA model. 


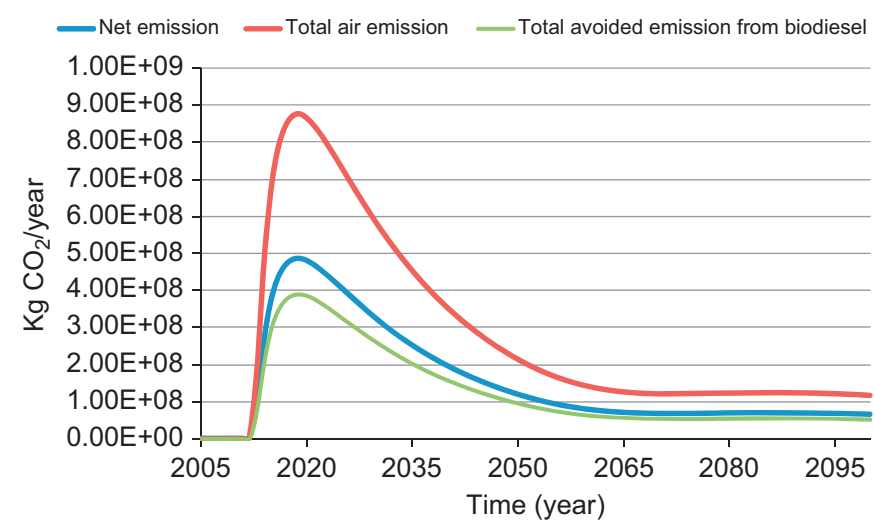

Fig. 8. Air emissions environmental indicator of the BIOTSA model.

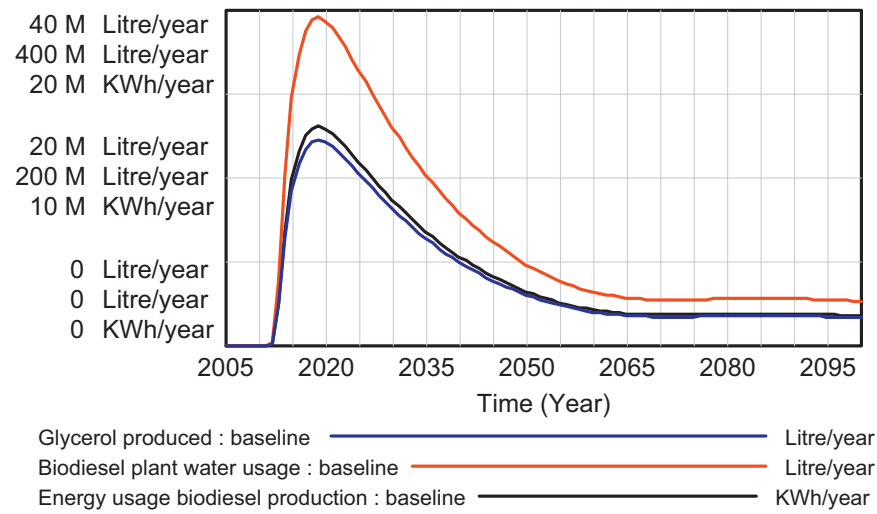

Fig. 9. Biodiesel by-product environmental indicator of the BIOTSA model.

\subsection{Scenario 1: Fertilizer use scenario (FUS)}

The fertilizer use scenario translates into the reduction of the land requirement per hectare for the production of the feedstock, for the same biodiesel production in baseline scenario (see Fig. 10a and b, respectively). While fertilizer use increases yield and leads to less land use than the baseline scenario, there is, however, an increase in the net air emissions (Fig. 10c). Thus, the fertilizer use scenario results in a trade-off in decreasing land use and increasing net air emissions. It should be noted that the study did not consider how the fertilizer would be provided and an assumption was that an institutional mechanism would definitely need to support local communities.

\subsection{Scenario 2a and 2b: Biodiesel support scenarios (BSS1 and BSS2)}

These scenarios are expected to increase the unit biodiesel profitability, which, in turn, influences the desired biodiesel capacity (see Fig. 11). The result shows that the biodiesel plant does not break-even with the doubling of biodiesel support. Given that BSS1 and BSS2 is not enough to drive the market penetration of large-scale biodiesel development, this prompted an investigation into the support that is needed to ensure that the biodiesel plant is profitable. This is indicated by BSS3 in Fig. 11, in which the biodiesel support used was 1.07 USD per litre ( 8 Rand/litre) Average exchange rate used: $1 \mathrm{USD}=7.5$ Rand. The results show that, with this scenario, the plant is capable of breaking even from the third year of its operation (Fig. 11a). In addition, the effect of the biodiesel profit on the desired capacity also increases over the simulation period (Fig. 11b).

The effect of the support scenario on selected indicators is shown in Fig. 12. The slight increase in the desired biodiesel capacity results in a slight increase in the biodiesel production, biodiesel cropland, employment in the biodiesel plant and total avoided emissions. Hence, it is clear that this scenario would only result in slight changes in the selected sustainability indicators. The only scenario that makes a visible difference is the hypothetical biodiesel support scenario of 1.07 USD per litre (BSS3).

\subsection{Scenario 3: By-product use scenario (BPS)}

Questions might arise in the biodiesel production concerning the effect of using the biodiesel by-product for revenue generation. Currently in South Africa, there is no market for locally produced glycerine, which may be attributed to its small- to medium-scale production. This study used a large-scale biodiesel production plant and it thus becomes necessary for the by-product use scenario. Fig. 13 illustrates an increase in the unit biodiesel profitability in comparison with the baseline scenario and the doubling of biodiesel support. It thus appears that the unit profitability in the biodiesel production would show a greater improvement with the incorporation of biodiesel by-products in the revenue generation process. However, some studies have found that increased biodiesel production will likely lead to the decrease in the value of the by-product (Amigun et al., 2008a); hence decreasing the biodiesel profitability. The extent of the decrease in profitability due to quality and purity of the glycerine will differ depending on the different stages of feedstock processing (Musango et al., 2012). However, this is beyond the scope of this study.

Considering the specific sustainability indicators that are affected by this scenario, it is observed in Fig. 14 that there is an increase in all the values of the indicators in comparison with the baseline and the biodiesel support scenario. These increases are, however, only visible from 2048 onwards and thus indicates the medium- to long-term benefit of utilizing the by-product in comparison to a situation without utilizing the by-product.

\subsection{Scenario 4: Community perception scenario (CPS)}

According to Amigun et al. (2011a), the local community's perception on growing crops for biodiesel production remains relatively low. This scenario tests a situation whereby the community perception is relatively high. It is evident in Fig. 15a that with a relatively high community perception, there is a large conversion of fallow land to biodiesel cropland. The implication is that more of the feedstock is sourced locally. While local feedstock production is available, biodiesel production (Fig. 15b) is not profitable yet and this leads to a reduction in the biodiesel production. However, after 2068, the biodiesel production begins to increase due to the combined effect of land availability, feedstock availability and improving profitability of the biodiesel production. Employment from biodiesel plant (Fig. 15c) and total avoided emissions (Fig. 15d) follows a similar trend as the biodiesel production.

\subsection{Scenario 5: Support and by-product use scenario (SBPS)}

It is apparent from the results in Fig. 16 that this scenario yields higher values of the sustainability indicators than the previous scenarios observed. However, the results of this scenario have only a slight difference with the by-product use scenario discussed previously.

\subsection{Scenario 6: Perception, support and by-product use scenario (PSBP)}

As can be seen in Fig. 17, this combined scenario has a high impact on the selected sustainability indicators relative to all other scenarios. This is primarily due to the combination of the 
a

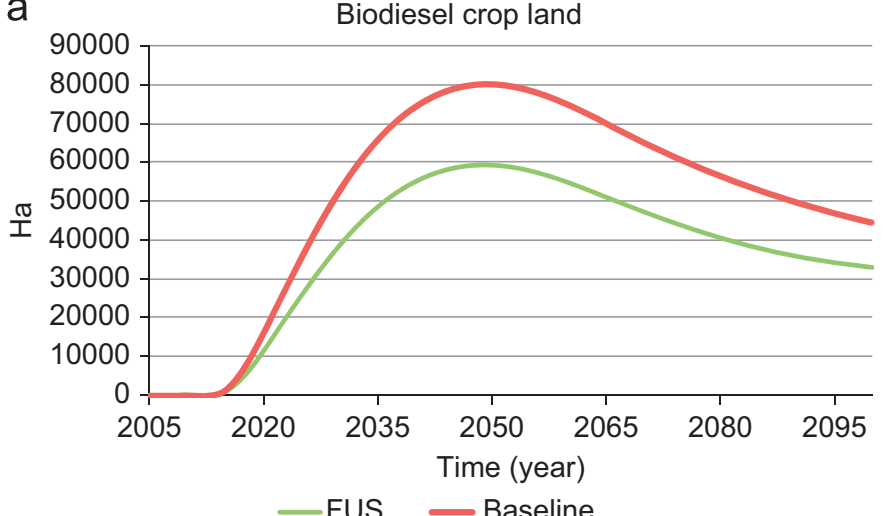

b

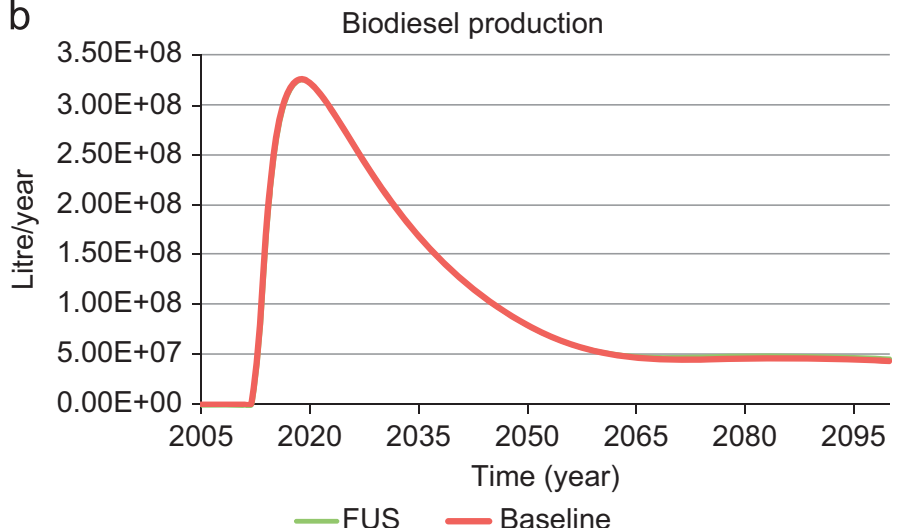

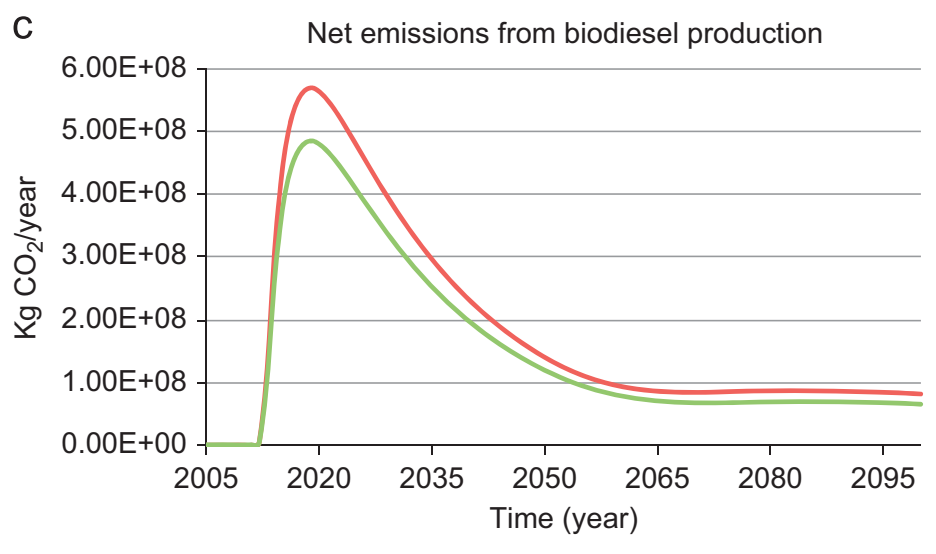

- FUS - Baseline

Fig. 10. Effect of fertilizer use scenario on selected indicators.

a

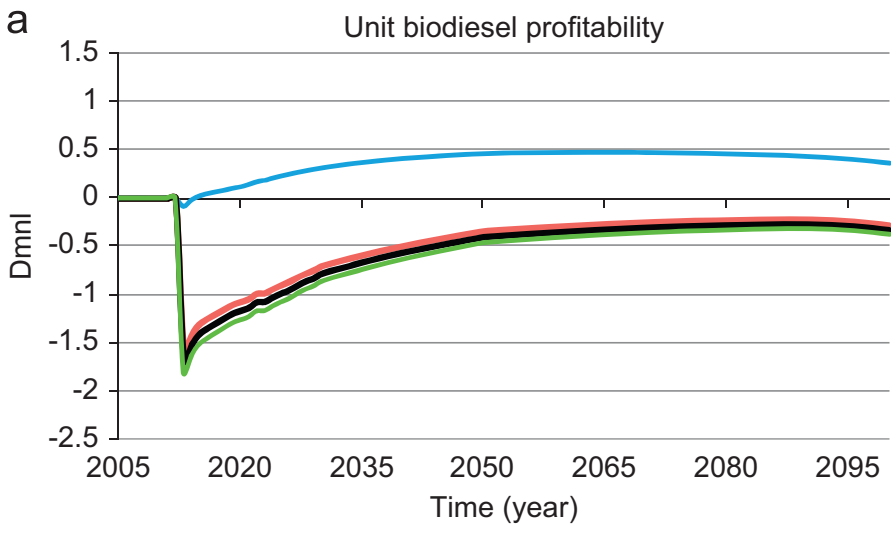

b

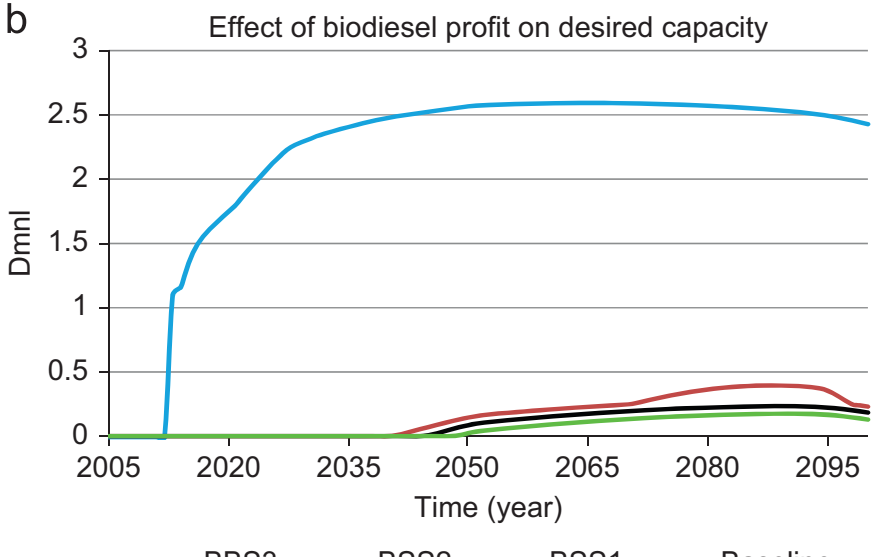

Fig. 11. Outcome of biodiesel support scenario.

availability of the local feedstock resulting from the willingness to convert fallow land to biodiesel cropland and the improved unit profitability due to support and sales of the biodiesel by-product. This illustrates the need for winning the community acceptance to participate in growing the biodiesel crops.

\section{Conclusions}

This paper utilised system dynamics modelling to evaluate the impact of biodiesel production development on selected sustainability indicators in the Eastern Cape Province, South Africa. The selected indicators included three economic; two social and five environmental; and mainly reflect the Eastern Cape Provincial issues of biodiesel production development. The model, Bioenergy Technology Sustainability Assessment (BIOTSA), which consists of eleven sub-models, categorised into economy, society and environment was utilized and is fully detailed in Musango et al. (2011c).

Six scenarios that were characterised by the different values of fertilizer use, biodiesel support, by-product use and community perception variables were defined and evaluated with reference to the baseline scenario. The baseline scenario is based on the assumptions that the biodiesel production will be operational in 2012 as per the investors' expectations; the operational costs for 
a

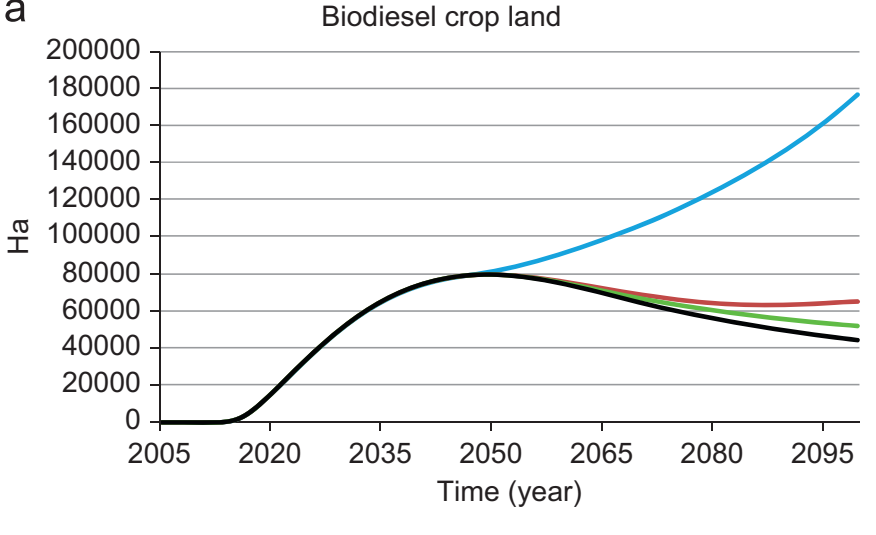

- BSS3 - BSS2 - BSS1 - Baseline

C

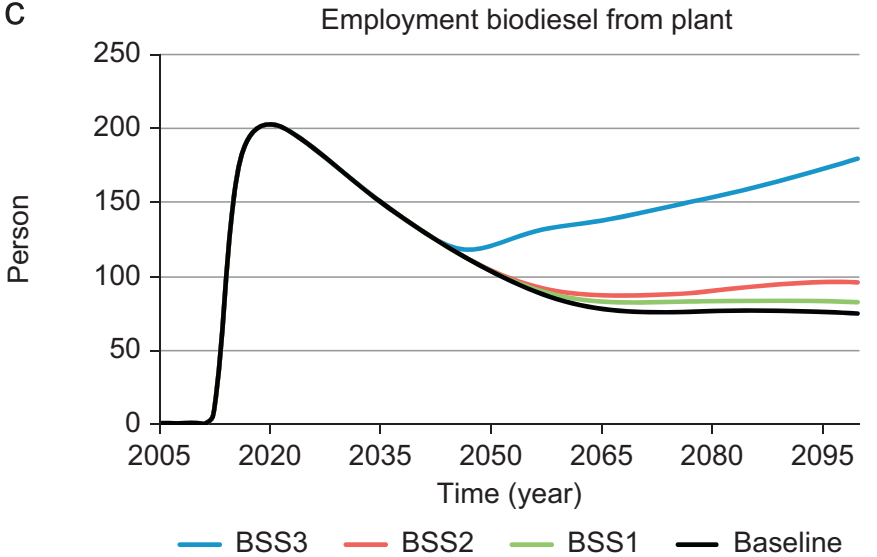

b

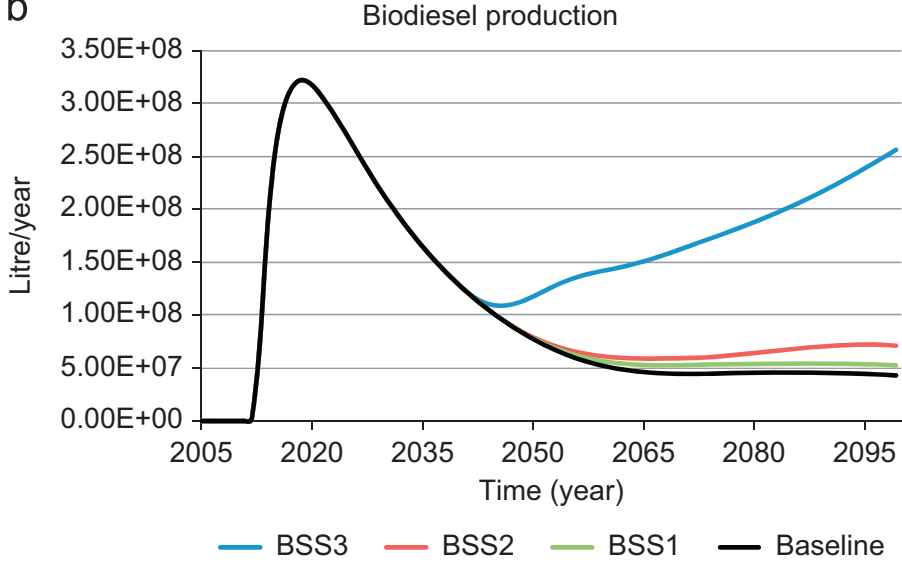

d

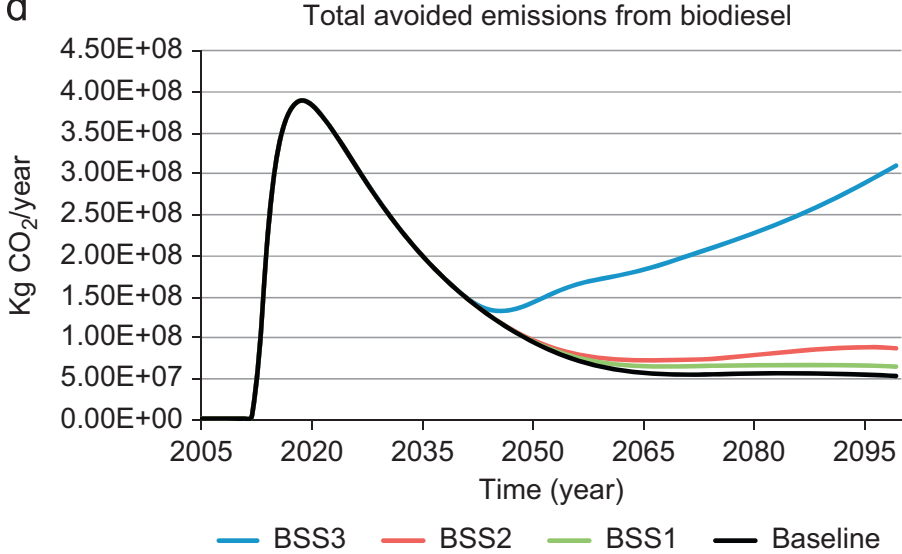

Fig. 12. Effect of biodiesel support scenario on selected indicators.

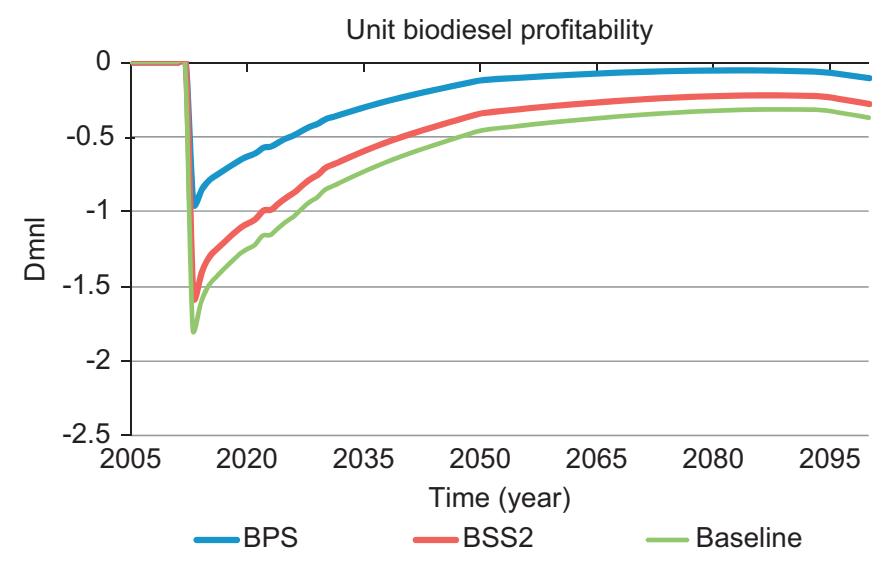

Fig. 13. Outcome of by-product use scenario.

biodiesel production grows at $0.1 \%$; the community perception to participate in biodiesel crop production remains relatively low; fertilizer is not being used in the biodiesel crops farming practices; and finally, no support in the form of subsidies is available to the farmers and the investors for their crop and biodiesel production, respectively.

From the baseline scenario, the dominant factors affecting the dynamics of the biodiesel production, an economic indicator, are the factors of land availability, biodiesel profit and feedstock availability. These factors influence the investors' desired biodiesel plant capacity factor, which, in turn, determines how much of the biodiesel development is functional. High cost of production is the prevalent factor affecting the biodiesel profitability, which is another economic indicator. High costs are attributed with the feedstock costs. Sourcing feedstock through imports has a much higher cost implication than from local production. Community perception, a social indicator, is also observed to play a key role in determining the amount of land converted for biodiesel production crops. With low community perception, biodiesel production development is bound to face a challenge of sourcing local feedstock, which, in turn, affects the profitability of the investments and hence the biodiesel production development. It is thus important to establish ways of improving the communities' perceptions by providing them with clarity of the positive and negative consequences of venturing into large-scale biodiesel production. This is a significant challenge as perceptions are likely to be resistant to change. The baseline results for environmental indicators ascertain that air emissions, waste production, water use and energy use follow similar dynamics as the biodiesel production, which is the dominant influence of these indicators.

The scenario analysis of biodiesel production development indicates that there is no single strategy that is capable of improving the performance of the selected sustainability indicators. To ensure sustainable biodiesel development, there is a need to account for combined strategies such as: support by the government on the biodiesel production; the use of by-products by the developers in revenue generation portfolio; and improvement of the local community perception.

While large-scale biodiesel production does not exist in South Africa, the scenario analyses were found to be rational and representative of the potential situation of biodiesel production development in the Eastern Cape Province. Therefore, the BIOTSA 
a

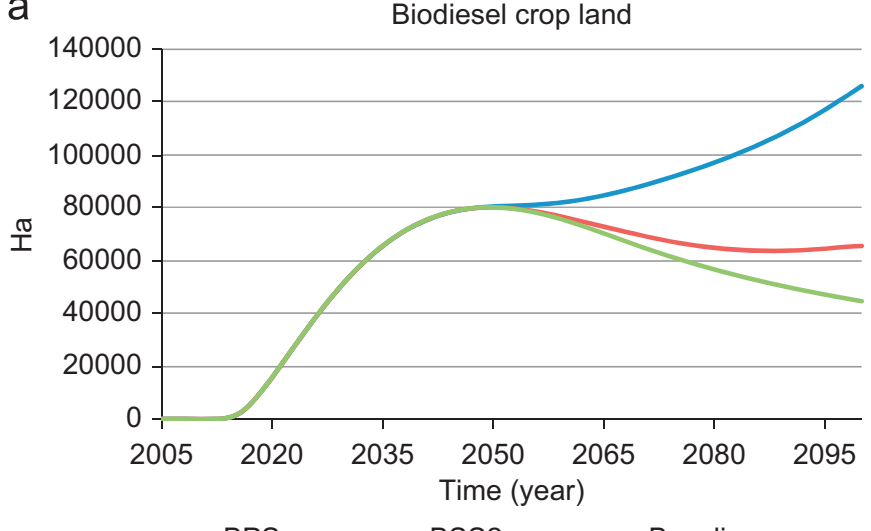

-BPS -BSS2 - Baseline

C

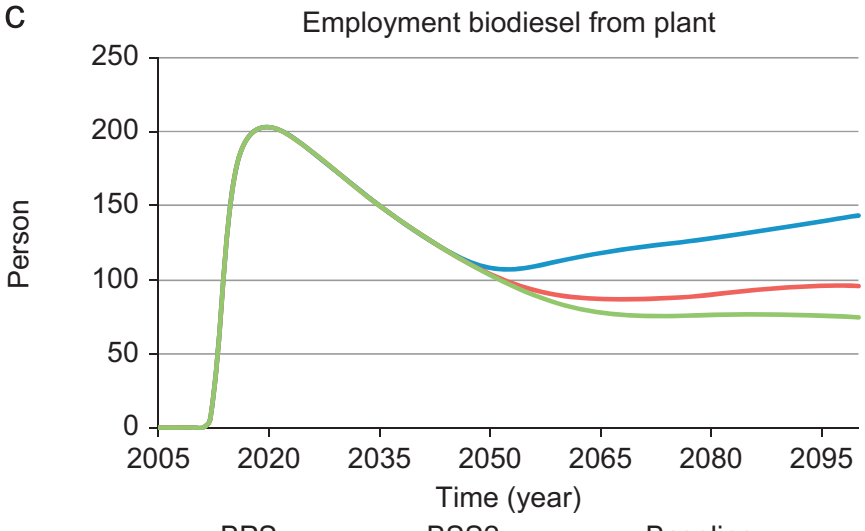

b

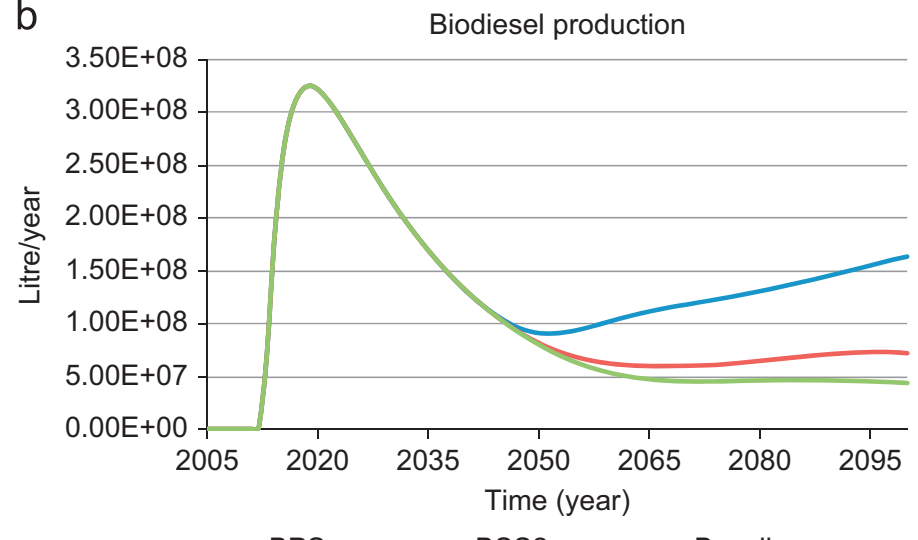

d

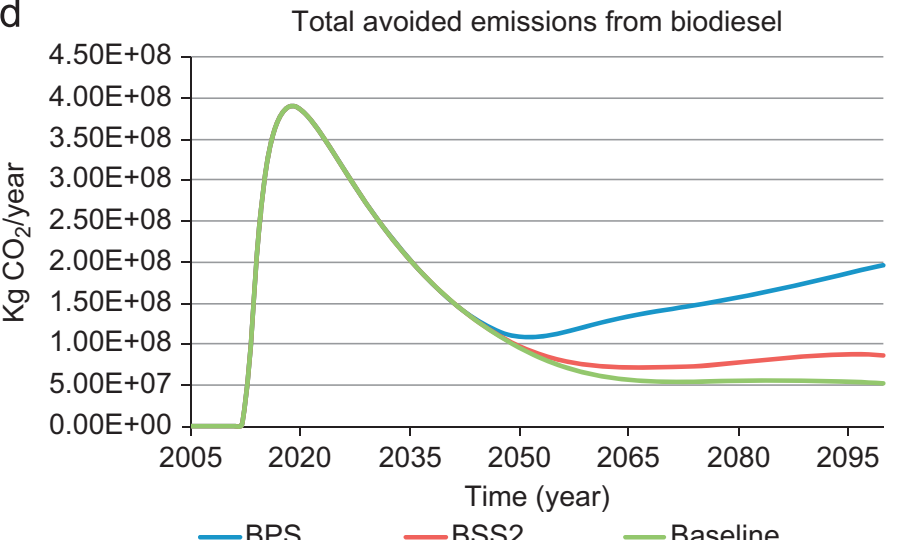

Fig. 14. Effect of by-product use scenario on selected indicators.

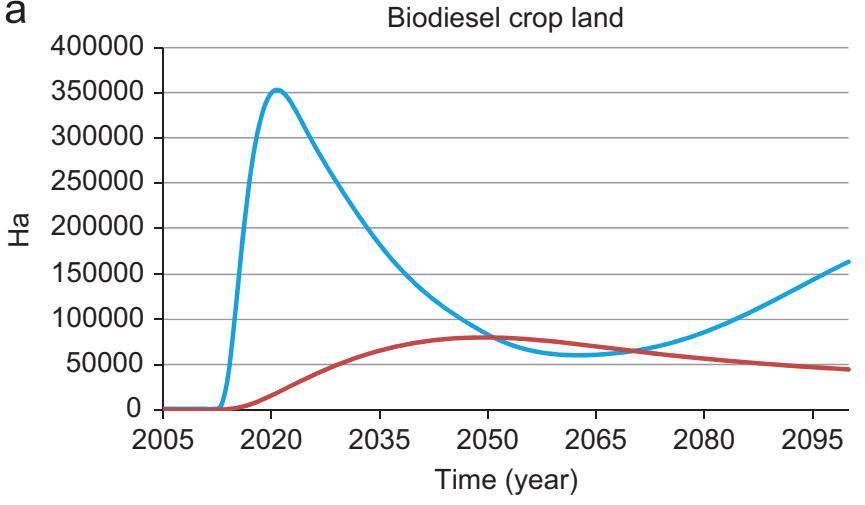

C

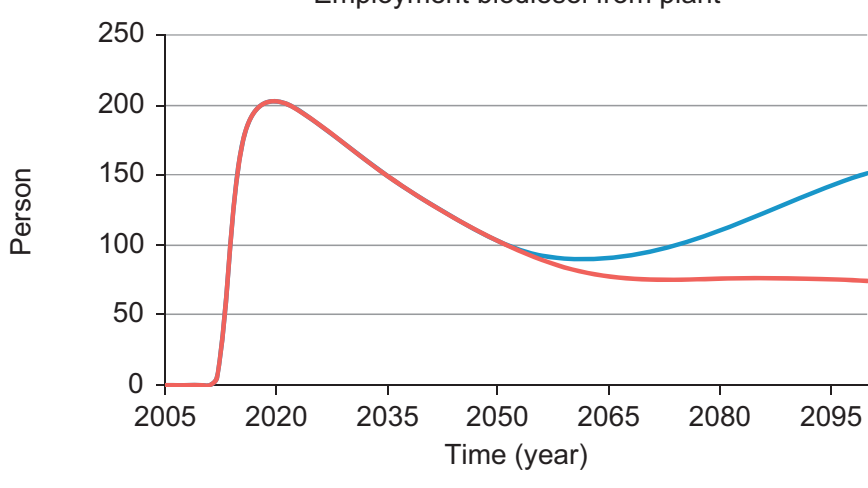

b

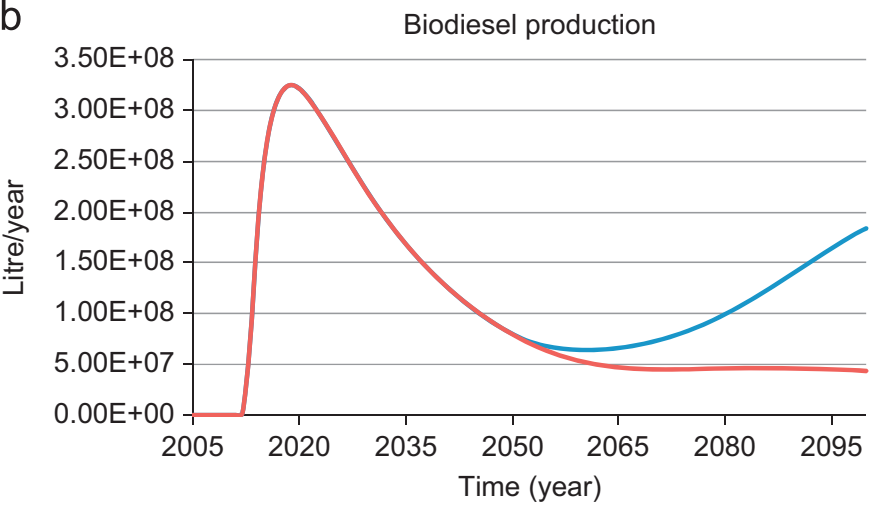

d

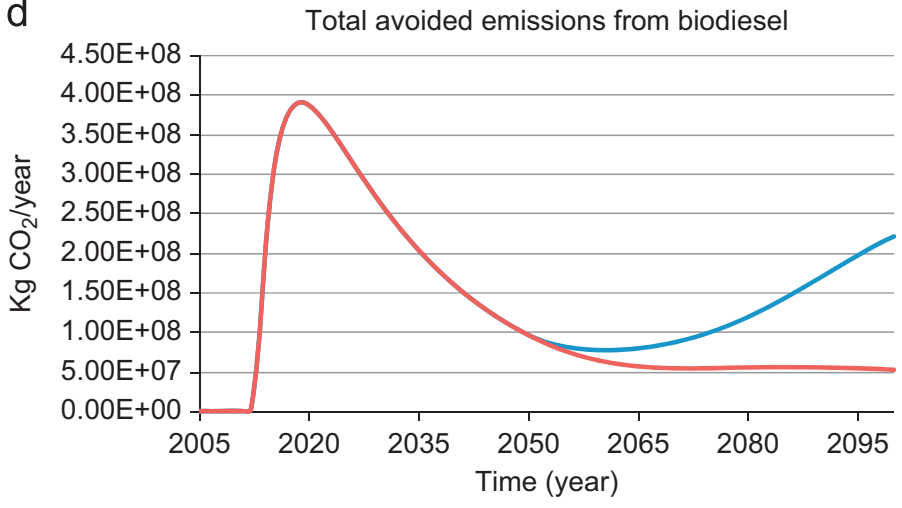

- CPS - Baseline

Fig. 15. Effect of community perception scenario on selected indicators. 
a

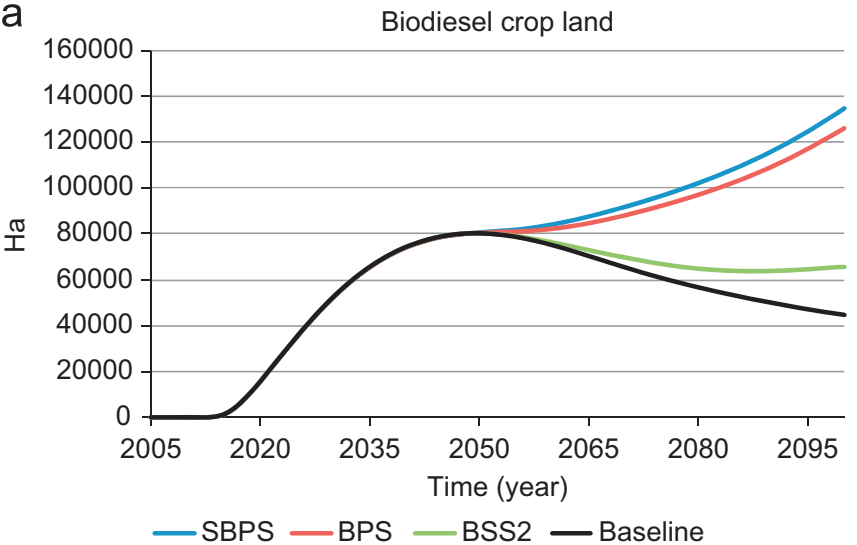

C

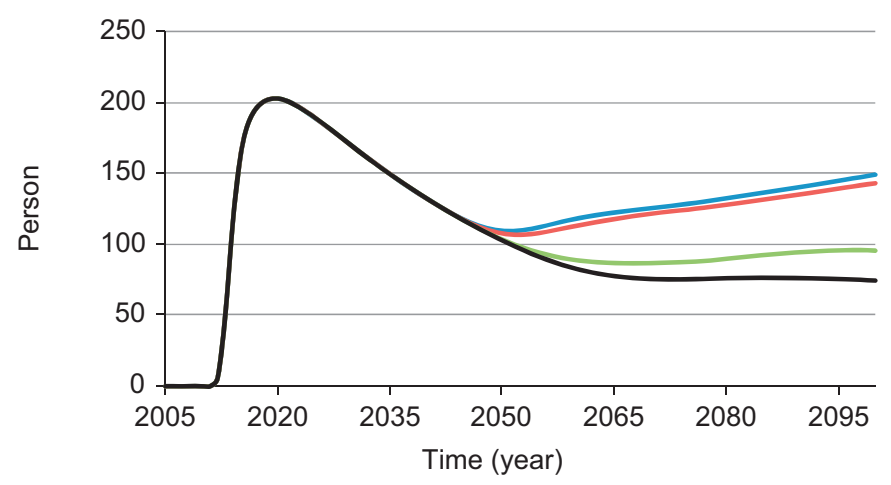

—SBPS —BPS - BSS2 - Baseline b

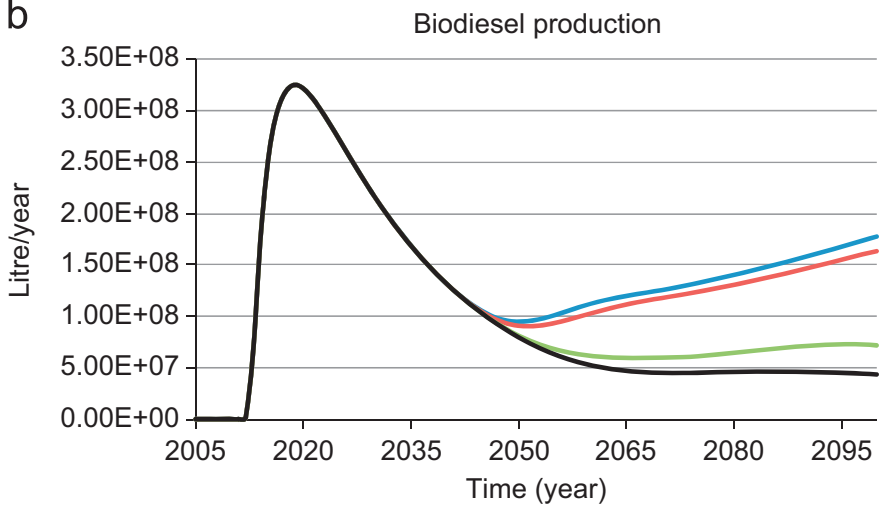

— SBPS — BPS — BSS2 - Baseline

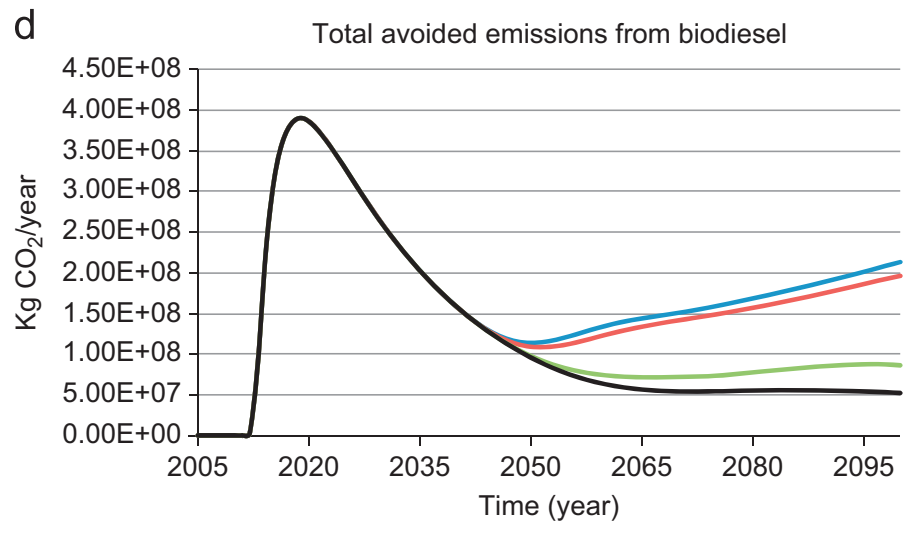

— SBPS —BPS - BSS2 — Baseline

Fig. 16. Effect of support and by-product use scenario on selected indicators.

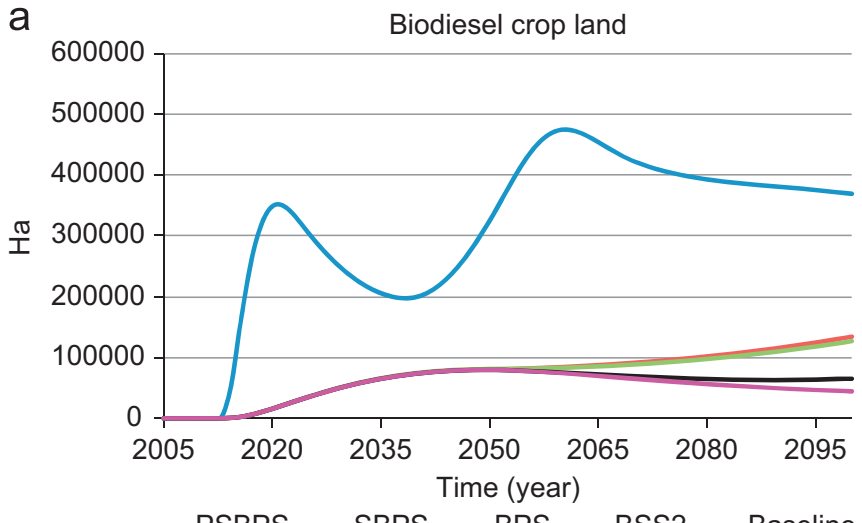

C

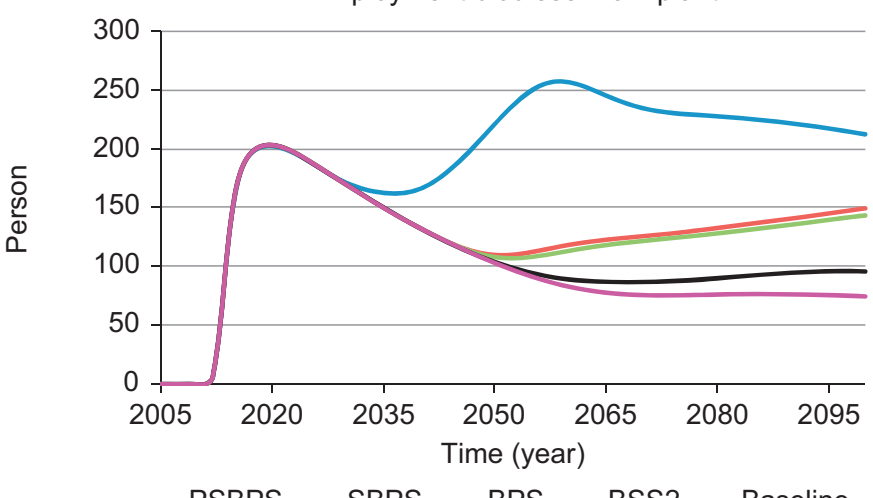

b

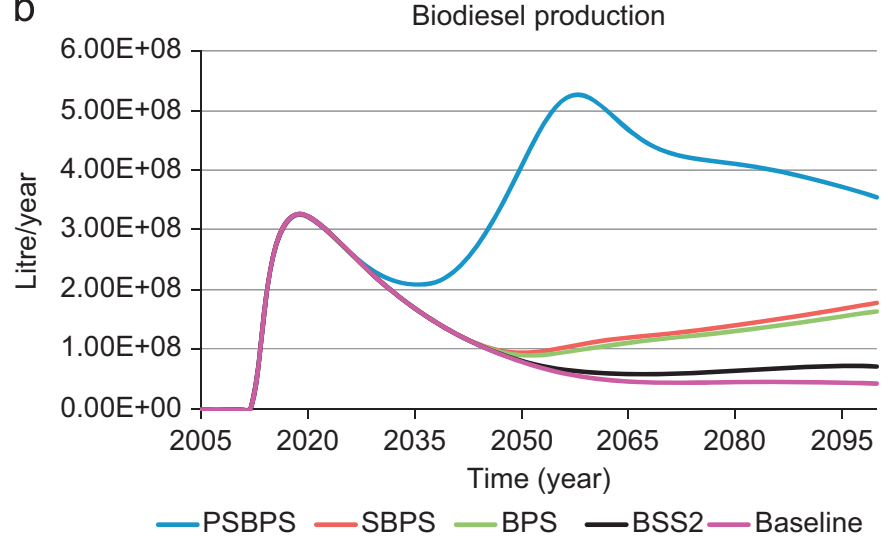

d

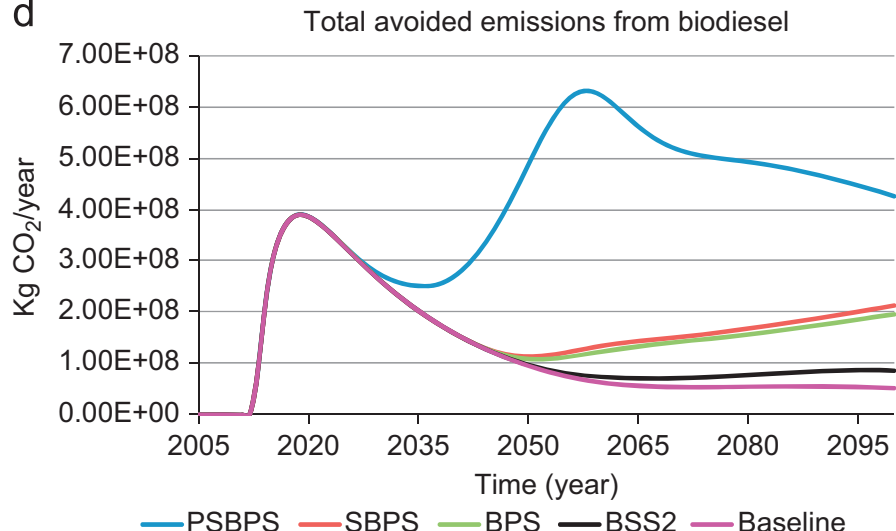

Fig. 17. Effect of perception, support and by-product use scenario on selected indicators. 
model demonstrates the meaningful application of the system dynamics approach to technology sustainability assessment. Because of simplification, robust assumptions were made, and future work to improve the usefulness and practicability of the model include exploring:

(i) the full value chain of the biodiesel production, namely wells-to-wheels:

(ii) a situation when the biodiesel plant is up and running to investigate communities perception in growing the crops for biodiesel production;

(iii) the different employment effects that may arise from biodiesel production which include: direct effect employment; indirect effect employment; and induced effect employment;

(iv) large-scale biodiesel production geared for the South African local market and considering the full value chain; and

(v) the impacts of small-scale biodiesel production in rural communities, which would require a different system dynamics model all together.

Finally, technology assessment practitioners in the South African public and private sectors were engaged to ascertain the extent to which this type of (quantitative) model may be used in the South African context for policy- and decision-making. These outcomes are detailed in Musango (2012).

\section{References}

Afgan, N.H., Carvalho, M.G., 2002. Multi-criteria assessment of new and renewable energy power plants. Energy 27 (8), 739-755.

Amigun, B., Musango, J.K., Brent, A.C., 2011a. Community perspectives on the introduction of biodiesel production in the Eastern Cape province of South Africa: questionnaire survey results. Energy 36 (5), 2502-2508.

Amigun, B., Musango, J.K., Stafford, W., 2011b. Biofuels and sustainability in Africa Renewable and Sustainable Energy Reviews 15 (2), 1360-1372.

Amigun, B., Müller-Langer, F., Weber, M., Von Blottnitz, H., 2008a. Predicting the costs of biodiesel production in Africa: learning from Germany. Energy for Sustainable Development 12 (1), 31-47.

Amigun, B., Sigamoney, R., Von Blottnitz, H., 2008b. Commercialisation of biofue industry in Africa: a review. Renewable and Sustainable Energy Reviews 12 (3), 690-711.

Assefa, G., Frostell, B., 2006. Technology assessment in the journey to sustainable development. In: Mudacumura, G., Mebratu, D., Haque, M.S. (Eds.), Sustainable Development Policy and Administration. Taylor and Francis Group, USA pp. 473-502.

Bantz, S.G., Deaton, M.L. 2006. Understanding U.S biodiesel growth using system dynamics modelling. Proceedings of the Systems and Information Engineering Design. (Accessed 23 March 2012), from: 〈http://www.sys.virginia.edu/ sieds06/papers/FMorningSession8.2.pdf $>$.

Basha, S.A., Gopal, K.R., Jebaraj, S., 2009. A review on biodiesel production, combustion, emissions and performance. Renewable and Sustainable Energy Reviews 13 (6-7), 1628-1634

Blagoev, M., Bizzari, S., Gubler, R., Funada, C., Yi, Z., 2008. Biodiesel. (Accessed 23 March 2012), from: 〈http://www.sriconsulting.com/CEH/Public/Reports/205. $0000 />$.

Brent, A.C., 2009. The principles of sustainability science to assess alternative energy technologies. International Association for the Management of Technology (IAMOT), Orlando, FL, USA.

Brent, A.C., Pretorius, M.W., 2008. Sustainable development and technology management. In: Sherif, M.H., Khalil, T.M. (Eds.), Management of Technology Innovation and Value Creation. Management of Technology 2. World Scientific, New Jersey, pp. 2008

Brent, A.C., Rogers, D.E., 2010. Renewable rural electrification: sustainability assessment of mini-hybrid off-grid technological systems in the African context. Renewable Energy 35 (1), 257-265.

Chan, A.W., Hoffman, R., Mcinnis, B., 2004. The role of systems modeling for sustainable development and policy analysis: the case of bio-ethanol. Ecology and Society 9 (2), 6 [online] URL: 〈http://www.ecologyandsociety.org/vol9/ iss2/art6 >.

Dangelico, R.M., Claudio, A.C., Petruzelli, A.M., 2010. A system dynamics model to analyze technology districts' evolution in a knowledge-based perspective. Technovation 30 (2), 142-153.

Department of Minerals and Energy., 2007. Biofuels industrial strategy of the Republic of South Africa. (Accessed 23 March 2012), from:〈http://www.info. gov.za/view/DownloadFileAction?id=77830 $>$.
De Piante Henriksen, A., 1997. A technology assessment primer for management of technology. International Journal of Technology Management 13 (5/6), 615-638.

Flood, R., Jackson, M., 1991. Creative problem solving: total systems intervention. John Wiley \& Sons Ltd, England.

Forrester, J.W., 1994. System dynamics, systems thinking and soft OR. System Dynamics Review 10 (2-3), 245-256.

Galanakis, K., 2006. Innovation process. Make sense using systems thinking. Technovation 26 (11), 1222-1232.

Hidayatno, A., Sutrisno, A., Zagloel, Y.M., Purwanto, W.W., 2011. System dynamic sustainability model of palm-oil based biodiesel production chain in Indonesia. International Journal of Engineering \& Technology 11 (3), 1-6.

Jones, C.A., 2008. The Renewable Energy Industry in Massachusetts as a Complex System: Developing a Shared Understanding for Policy Making, Ph.D. Dissertation, University of Massachusetts, Boston.

Kilham, S., Willetts, J., (Undated) Transdisciplinary research: a new opportunity for understanding Timor-Leste. (Accessed 23 March 2012), from: 〈http://www. tlstudies.org/pdfs/chp55a.pdf $>$.

Kim, B., 2003. Managing the transition of technology life cycle. Technovation 23 (5), 371-381.

Lin, C-H., Tung, C-M., Huang, C-T., 2006. Elucidating the industrial cluster effect from a system dynamics perspective. Technovation 26 (4), 473-482.

Meyer, P.E., Winebrake, J.J., 2009. Modelling technology diffusion of complimentary goods: the case of hydrogen vehicles and refuelling infrastructure. Technovation 29 (2), 77-91.

Musango, J.K., 2012. Technology Assessment of Renewable Energy Sustainability in South Africa, Ph.D. Thesis, Faculty of Economics and Management Sciences, Stellenbosch University.

Musango, J.K., Brent, A.C., 2011a. A conceptual framework for energy technology sustainability assessment. Energy for Sustainable Development 15 (1) 84-91.

Musango, J.K., Brent, A.C., 2011b. Assessing the sustainability of energy technological systems in Southern Africa: A review and way forward. Technology in Society 33 (1-2), 145-155

Musango, J.K., Brent, A.C., Amigun, B., Pretorious, L., Müller, H., 2011. Technology sustainability assessment of biodiesel development in South Africa: a system dynamics approach. Energy 36 (12), 6940-6992.

Pahl, G., 2008. Biodiesel: Growing a New Energy Economy. Chelsea Green Publishing Company, USA.

Rose-Anderssen, C., Allen, P.M., Tsinopoulos, C., McCarthy, I., 2005. Innovation in manufacturing as an evolutionary complex system. Technovation 25 (10), $1093-1105$.

Sterman, J.D., 2000. Business Dynamics: Systems Thinking and Modelling for a Complex World. McGraw-Hill/Irwin, New York.

Sukkasi, S., Chollacoop, N., Ellis, W., Grimley, S., Jai-In, S., 2010. Challenges and considerations for planning toward sustainable biodiesel development in developing countries: lessons from the Greater Mekong Subregion. Renewable and Sustainable Energy Reviews 14 (9), 3100-3107.

Synder, N., Antkowiak, M., 2010. Applying systems engineering in a renewable energy research and development environment, National Renewable Energy Laboratory, NREL/CP-6A1-48159, INCOSE International Symposium, Chicago. (Accessed 23 March 2012), from: 〈http://www.nrel.gov/docs/fy10osti/48159. pdf $>$.

Tran, T.A., Daim, T., 2008. A taxonomic review of methods and tools applied in technology assessment. Technological Forecasting and Social Change 75 (9) 1396-1405.

Van Zyl, W.H., Prior, B.A., 2009. South Africa Biofuels: Taskgroup 39 Progress Report. (Accessed 23 March 2012), from: <http://academic.sun.ac.za/biofuels/ Media\%20info/South\%20Africa\%20Biofuels\%20May\%202009\%20Progress\%20Re port.pdf $>$.

Ventana Systems., 2003. Vensim ${ }^{\mathbb{R}}$ Standard Professional DSS Tutorial Harvard, 60 Jacob Gates Road USA.

Josephine K Musango is a Senior Researcher with Gauteng City-Region Observatory, which is an institutional partnership between University of Johannesburg, University of Witwatersrand and the Gauteng Provincial Government. She holds a Masters Degree in Agricultural Economics from Stellenbosch University. Her research interest is undertaking transdisciplinary research focused on integrating economics into sustainable resource management and solving complex social and environmental problems through application of economic analysis and system dynamics modelling. Her particular interests are on social, environmental and resource management and policy challenges including energy, climate change, water, land use and waste management. She has published widely in peer reviewed Journals and in international and local Conferences. She recently completed her PhD degree (in Sustainable Development) at the School of Public Leadership at the Stellenbosch University, which will be conferred in 2012 academic year as per the policies of the University. Her PhD thesis was on "Technology Assessment of Renewable Energy Sustainability in South Africa". 
Alan C Brent is the associate director of the Centre for Renewable and Sustainable Energy Studies, and a professor of Sustainable Development in the School of Public Leadership, at Stellenbosch University, South Africa. He is also a part-time professor of Sustainable Life Cycle Management in the Graduate School of Technology Management at the University of Pretoria, South Africa. He holds, among other degrees, a Bachelor of Engineering in chemical engineering, a Bachelor of Philosophy in sustainable development, a Master of Science in environmental engineering, a Master of Engineering in technology management, and a doctorate in Engineering Management. He has extensive experience in a variety of industry and public sectors in South Africa and other developing countries in the fields of environmental engineering and management, and the sustainability of technologies in general.

Bamikole Amigun (deceased) held a Ph.D. in Chemical Engineering (Renewable Energy Development and Economics) from University of Cape Town, and a Masters in Chemical (Environmental and Proces Engineering) Engineering. He was a bioenergy expert and specialised in the development and application of economic models in renewable energy technologies with special focus on the African continent and resource conversion to energy. He also specialised in the conversion of resources using the bio-refineries approach, sustainability assessment and prioritisation of technologies using social, environment and economic indicators; long term economic viability; risk assessment of energy technologies; process/plant optimisation and energy efficiency (DSM). Bamikole also utilised the system dynamics approach to further understand the behaviour of energy technologies over time. He served as a reviewer for academic journals and research proposals (for organisations and institutions both within and outside South Africa) and was external examiner for Masters and Ph.D. researchers. He published widely and presented at both local and international conferences, some as plenary speaker. He was a biofuel technical committee member of the African Roundtable on Sustainable Consumption and Production (ARSCP) - a UNEP initiative. Unfortunately, Bamikole tragically and suddenly passed away in June 2012.
Leon Pretorius has more than 30 years professional, engineering, academic, and academic management experience. He holds the degree Doctor of Engineering as well as a Masters degree in Mathematics from the University of Pretoria. He was professor at the University of Johannesburg, South Africa until 2007. In 2004 he was the last Dean of Engineering at the Rand Afrikaans University prior to the merger of RAU and TWR when he became Co-Executive Dean of Engineering and the Built Environment at the University of Johannesburg in 2005. He is currently Professor in the Graduate School of Technology Management at the University of Pretoria. He has supervised the theses of more than 160 Master and PhD students. He has concurrently been active as specialist consultant and researcher in engineering industry in therma and dynamic systems including CFD as well as engineering and technology management since 1980 .
Hans Müller is the Director of Centre for Knowledge Management and Decision-making at Stellenbosch University, South Africa. Previously, he has been a Visiting Research Fellow in the Department of Sociology at University of Tilburg and University of Louvain. He holds a doctorate degree in Philosophy, Masters Degree in Philosophy, Bachelor of Theory and Bachelor of Arts, all from Stellenbosch University. He has published internationally and edited a book, and has 5 chapters in books. He is currently supervising 4 doctoral students and has 17 research Masters completed. He is also a member of several associations and a reviewer for various journals. 